\title{
Private Investment in Higher Education: Comparing Alternative Funding Schemes
}

\author{
BERNHARD ECKWERT \\ ITZHAK ZILCHA
}

\section{CESIFO WORKING PAPER NO. 2395 \\ CATEGORY 1: PUBLIC FinANCE \\ SEPTEMBER 2008}
An electronic version of the paper may be downloaded
- from the SSRN website: Www.SSRN.com
- from the RePEc website:
- from the CESifo website:




\title{
Private Investment in Higher Education: Comparing Alternative Funding Schemes
}

\begin{abstract}
This paper uses an overlapping generations framework to analyze the implications of different financing regimes in the education sector for human capital formation and economic welfare. Agents privately invest in education after they have received a noisy information signal about their abilities. The incentives of the individuals to invest in education are determined by the financing regime under which the economy operates. The paper analyzes and compares three financing regimes. Under each regime, the payback obligation of an educational loan is contingent, to some extent, on an individual's future income.
\end{abstract}

JEL Code: D31, D91, H31, I22.

Keywords: higher education, funding regimes, human capital, welfare.

\author{
Bernhard Eckwert \\ Bielefeld University \\ 33501 Bielefeld \\ Germany \\ beckwert@wiwi.uni-bielefeld.de
}

\author{
Itzhak Zilcha \\ Tel Aviv University \\ The Eitan Berglas School of Economics \\ P.O.B. 39040 \\ Ramat Aviv, Tel Aviv, 69978 \\ Israel \\ izil@post.tau.ac.il
}

May 2008

We are grateful to Moshe Buchinsky, Burkhard Drees, Geoffrey Kingston, Ady Pauzner, and Yoram Weiss. Financial support from the German-Israeli Foundation for Scientific Research and Development (GIF) is gratefully acknowledged. 


\section{Introduction}

Ample empirical evidence shows that higher education is an important element in generating personal incomes and in promoting the economic performance of countries [see, Barro (1998), Bassinini and Scarpenta (2001), Restuccia and Urrutia (2004). Consistent with this finding, investment in the education sectors of the OECD countries has increased substantially during the second half of the twentieth century [Greenaway and Haynes (2003), Checchi (2006)]. Yet, the expansion of higher education has often collided with fiscal pressures, thereby creating a tendency to shift the financial burden of an expanding education sector away from public funding towards private funding. ${ }^{1}$ In particular, some European countries have recently substituted various forms of income support transfers with programs based on student loans. On balance, this process has resulted in a significant decline of public funding per student.

The shift towards private funding of higher education is sometimes justified with reference to an egalitarian income distribution. On average, students have a better socio-economic background and, hence, higher income prospects than other members of society. Therefore, public subsidies of higher education constitute an implicit monetary transfer from the poor towards the more affluent individuals. This problematic aspect of public funding has been pointed out by Friedman in his famous contribution on Capitalism and Freedom in 1962.

In addition, as long as frictionless financial markets (for private education financing) exist, individual abilities will be used efficiently in the production process under a private funding scheme. In reality, however, financial markets for education financing are imperfect and sometimes even non-existent. Young individuals often cannot provide sufficient collateral which would allow them to borrow against their future incomes. Therefore, a structural change away from public funding towards private funding requires the provision of suitable loan programs which remove financial barriers for the young generation to participate in the higher education system. Ideally, such loan programs would also provide some diversification of individual

\footnotetext{
${ }^{1}$ Even in Russia $47 \%$ of the students in the higher education system must finance their tuition fees (which are significant), as well as other related costs from their own resources [see Kaganovich (2005)].
} 
income risks within a given cohort of agents.

Thus, moving from public funding towards private funding of higher education generally induces a trade-off in terms of economic welfare which results from interacting efficiency effects and equity effects. What are the main ingredients of a financing scheme which optimally combines the efficiency and equity effects in light of this trade-off? Friedman $(1955,1962)$ was the first to raise this issue and to suggest income-contingent financing of students' investments in higher education. $^{2}$ Friedman argues that the use of income-contingent loans for the finance of higher education is recommendable because it allows individuals to sell 'shares' in their random future income streams in order to finance their educational investments. These shares will be bought by investors who can 'diversify' their holdings

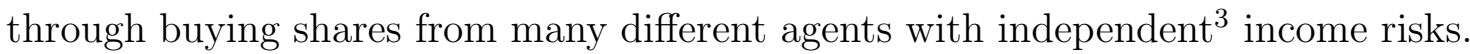
The diversification process drives down the expected return on the shares to the market rate of interest. This mechanism ensures that individuals can finance their educational investments on favorable terms, thereby avoiding an economy-wide underinvestment in education.

Friedman's suggestion is not explicit about the precise way in which the repayment should be linked to individual income. In particular, it is not clear whether all students should be offered the same terms of repayment or whether these terms might take into account certain individual characteristics which are correlated to an agent's future earning prospects. In this paper we reconsider this issue. Our aim is to analyze the implications of alternative income-contingent financing schemes for higher education differing mainly in the degree of risk pooling that they involve. The Friedman-argument suggests that the overall investment process in an education sector with income-contingent loans finance is more efficient, if individual income risks are pooled more comprehensively. Our analysis shows that, in general,

\footnotetext{
${ }^{2}$ More recently, various forms of integrating income-sensitive elements into financing schemes for higher education have been discussed in Barr and Crawford (1988) and in Greenaway and Haynes (2003). The design of student loan programs, repayment and debt default, as well as some international experience has been discussed by Woodhall (1988) and Lleras (2004). Albrecht and Ziderman (1993) provide evidence on loans collectibility and on the cost of such programs.

${ }^{3}$ More precisely, Friedman (1955) is talking about individual incomes that are subject to risks which can be completely eliminated by pooling. This property is not always equivalent to assuming that individual income risks are independent.
} 
this conjecture is not true. In fact, the process which transforms aggregate investment in education into aggregate human capital can be improved by restricting risk pooling to certain subgroups of agents.

We conduct our analysis in the framework of an overlapping generations model with endogenous human capital formation. Models of this type were used, for example, by Azariadis and Drazen (1990), Orazem and Tesfatsion (1997), Viaene and Zilcha (2002). Individuals are randomly endowed with innate abilities. When young, the agents learn an imperfect signal of their ability (or future income), and then chose their investment in education.

We distinguish between three financing regimes which specify the terms of repayment for education loans. Under the first regime, the government guarantees students unrestricted access to competitive credit markets. The government also guarantees enforcement of debt collection. The second regime links the repayment of a loan to an agent's future income in a way which allows risk pooling across all members in the same generation. The third regime also links the terms of repayment to future income, but in a 'narrower' sense which supports pooling of income risks only among individuals in the same signal group. The second regime cannot be decentralized in a competitive financial market setting, and it has major drawbacks with regard to the efficiency of the human capital formation process. Therefore, this regime serves mainly as a standard of comparison for the other two regimes.

As a main result we find that a repayment scheme that allows pooling of income risks within signal groups (third regime) stimulates investment in education and economic growth compared with a funding scheme of competitive credit markets (first regime). The intuition for this result is rather straightforward: in each signal class under the third regime, agents' residual risks are insured which leads them to invest more. Also, the third regime generates higher welfare than the first regime. Under the third regime economic growth is higher than under the second regime, even though aggregate investment in education may be lower. The welfare comparison between the second and the third financing regimes can be characterized in terms of technological and preference parameters.

The paper is organized as follows. We present our model and the above mentioned three financing regimes in Section 2. Section 3 examines the implications of 
these financing schemes for investment in education and human capital accumulation. Section 4 compares the welfare implications of these funding schemes. Section 5 concludes the paper. All proofs are relegated to the Appendix.

\section{The Model}

We consider an overlapping-generations economy with a single commodity, say, physical capital, which can be consumed or invested in production. Individuals live for three periods: the 'youth period', where each individual is supported by parents. In this period, the agent takes out a loan and makes a capital investment in education in order to acquire skills; the 'middle period', where individuals work, earn labor income, consume and save. Labor income depends on each agent's skills, or human capital, which is assumed to be observable. Part of the labor income is earmarked for the repayment of the loan. Finally, the 'retirement period' in which individuals consume their total savings. There is no population growth and each generation $G_{t}$ (i.e., all individuals born at date $t-1$ ), $t=0,1,2 \ldots$, consists of a continuum of agents with (Lebesgue-) measure 1 , say the interval $[0,1]$.

Our framework is characterized by heterogenous individuals in each generation, where heterogeneity is generated by random innate ability. While nature assigns abilities to individuals at birth, no individual knows exactly his own ability when, at young age, he invests privately in education. Therefore, the investment decision, $x$, is made under uncertainty. In the next period, the agent learns his ability $A$. We denote by $\nu(A)$ the time-invariant density of agents with ability $A$, where $A \in \mathcal{A}$ for some closed interval $\mathcal{A} \subset \mathbb{R}_{++}$. From the perspective of a young individual, ability is random as it is the realization of a random variable with distribution $\nu(\cdot)$. Yet, there is no aggregate uncertainty in the economy, i.e., the ex post distribution of abilities across the members of a generation is exactly $\nu$. Our modeling approach follows the technique suggested in Feldman and Gilles [1985, Proposition 2], where uncertainty exists at the individual level but in the aggregate there is no uncertainty.

The production function of human capital is, in general, a complex function which depends on individual, family, and other parameters. We shall restrict the structure of the human capital formation process, in order to make our equilibrium 
comparative dynamics analytically manageable. We assume that the level of human capital, or skills, of an individual $i \in G_{t}$, denoted by $h_{t}^{i}$, depends on the (random) innate ability $A^{i}$, the private investment in education $x^{i} \in \mathbb{R}_{+}$, and the average human capital of the older generation, denoted by $H_{t-1}$ (which may represent the human capital of 'teachers'). Namely,

$$
h^{i}=A^{i} g\left(x^{i}, H_{t-1}\right)
$$

Public investment in individual education, which is assumed to be the same for all agents, is included in the accumulation function, $g$, through some implicit additive component. We make the following assumption about this process:

Assumption $1 \mathrm{~g}(x, H)$ is twice differentiable, strictly increasing and concave in the first argument, and satisfies $\lim _{x \rightarrow 0} g_{1}^{\prime}(x, H)=\infty$ for $H>0$. Also $g_{1}^{\prime}(x, H)$ is non-decreasing in H. Furthermore,

$$
K(x, H):=-\frac{g_{11}^{\prime \prime}(x, H)}{g_{1}^{\prime}(x, H)}
$$

is non-increasing in $x$, i.e., $K_{1}^{\prime}(x, H) \leq 0 \forall x, H$.

$K(x, H)$ is a measure of concavity (with respect to $x$ ) of the accumulation function $g$. By Assumption 1, this measure of concavity is decreasing in $x$ which implies that $g_{1}^{\prime}(x, H)$ is convex in $x$. Thus, the marginal product of investment in education decreases at a declining rate. This restriction is satisfied by most functional forms commonly used in the literature to describe the transformation of educational investment into human capital formation.

Each agent chooses private investment in education after he has learned a publicly observable signal $y \in Y \subset \mathbb{R}$ of his ability $A$. Students receive such signals before they enter higher education. Examples include personality tests and matriculation examinations used by universities to screen the field of applicants. The test results are noisy but they are correlated with the characteristics that have been tested.

Within the group of agents with ability $A$, the signals are distributed according to the density $\nu_{A}(y)$. The signal assigned to an agent can be used as a screening 
device for his unknown ability. Based on the screening information conveyed by the signal, the agent forms expectations about his ability in a Bayesian way. The distribution of signals received by agents in the same generation has the density $\mu(y)=\int_{\mathcal{A}} \nu_{A}(y) \nu(A) \mathrm{d} A$. Average ability of all agents who have received the signal $y$ is $\bar{A}_{y}:=E[\tilde{A} \mid y]=\int_{\mathcal{A}} A \nu_{y}(A) \mathrm{d} A$, where $\nu_{y}(A)$ denotes the density of the conditional distribution of $A$ given the signal $y$.

In our model both the signals and the investments made by individuals in their education are publicly observable. We assume throughout the paper that the Monotone Likelihood Ratio Property (MLRP) holds, i.e., the signals are ordered in such a way that $y^{\prime} \geqslant y$ implies that the posterior distribution of ability conditional on $y^{\prime}$ dominates the posterior distribution of ability conditional on $y$ in the first-degree stochastic dominance. In this sense, higher signals are 'good news' [see, Milgrom (1981)].

Each young individual needs a loan in order to finance his investment in education. The terms of repayment are subject to government intervention. We shall consider three different forms of government intervention in the market for education loans:

1. Regime I (Unrestricted Access to Credit Markets): Under this regime the government guarantees each student unrestricted access to credit markets for funds needed to finance higher education. The government also guarantees enforcement of debt collection, e.g., through levies on wages.

2. Regime II (Unrestricted Insurance of Loans): Under this regime the terms of repayment of a loan are linked to the realization of an individual's future income (hence, linked to the realization of his human capital). This insurance arrangement pools the risks of all young agents in the same cohort who choose to invest in education. The governmental intervention includes releasing information about individual incomes, as well as guaranteeing the collection of debt.

3. Regime III (Restricted Insurance of Loans): Again, the terms of repayment are linked to random individual future incomes. Yet, the insurance arrangement pools the risks within each signal group (group of agents who have 
received the same signal) separately.

We shall study these three financing regimes separately, assuming that the same regime applies to all agents. Thus, in our economy only one regime prevails; in particular, students cannot choose between a loan in the credit market with uncontingent terms of repayment (Regime I) and a loan with contingent repayment (Regimes II or III). This assumption seems reasonable because the implementation of any regime requires some government intervention. ${ }^{4}$ Hence, the regimes do not emerge, and compete against each other, endogenously. Rather, they should be viewed as political choice variables. The implications of those political choice variables for the time path of aggregate human capital and welfare will be analyzed below.

Regime II serves as a benchmark in our analysis. In some European countries like Germany funding concepts for higher education in the spirit of Regime II have been discussed in the 70s. While this regime may have some appeal from the viewpoint of an egalitarian income distribution, it has major drawbacks in terms of inefficiencies for the human capital formation process. In addition, Regime II must be enforced by the state; it cannot be sustained as a market equilibrium because banks would ask to see peoples' signals and offer individuals with high signals loans on better terms than individuals with low signals. Therefore, in this paper we treat Regime II mainly as a standard of comparison for the other two regimes.

The agents are expected utility maximizers with von-Neumann Morgenstern lifetime utility function

$$
U\left(c_{1}, c_{2}\right)=u_{1}\left(c_{1}\right)+u_{2}\left(c_{2}\right) .
$$

$c_{1}$ and $c_{2}$ denote consumption in the second and third period of life, respectively. In his first period of life each agent makes a capital investment in education, but he does not consume. The utility functions $u_{i}: \mathbb{R}_{+} \rightarrow \mathbb{R}, i=1,2$, are strictly increasing and strictly concave.

In each period, competitive firms produce a commodity that can be used for consumption. The firms use physical capital, $K$, and human capital, $H$, as production

\footnotetext{
${ }^{4}$ This holds true even for Regime I. Given the evidence about borrowing constraints that students face in the financial markets (see, e.g., Galor and Zeira (1993)), some intervention by the government is needed to implement the regime.
} 
factors. Physical capital fully depreciates in the production process. We describe the production process by an aggregate production function $F(K, H)$, which exhibits constant returns to scale. In his 'working period' each agent $i$ inelastically supplies $l$ units of labor and, hence, his supply of human capital is $l h^{i}$. Without loss of generality, we set $l=1$. The production function has the following properties:

Assumption $2 F(K, H)$ is concave, homogeneous of degree 1, and satisfies $F_{K}>$ $0, F_{H}>0, F_{K K}<0, F_{H H}<0$.

Physical capital is internationally mobile while human capital is assumed to be immobile. ${ }^{5}$ This implies that the interest rate, $\bar{r}_{t}$, is exogenously given at each date (small country assumption). Having assumed full depreciation of physical capital in each period, marginal productivity of aggregate physical capital, $K_{t}$ equals $1+\bar{r}_{t}$. Thus, given the aggregate stock of human capital at date $t, H_{t}$, the stock of physical capital, $K_{t}$, adjusts such that

$$
R_{t}:=1+\bar{r}_{t}=F_{K}\left(K_{t}, H_{t}\right) \quad t=1,2,3, \cdots
$$

is satisfied. This implies by Assumption 1, that $K_{t} / H_{t}$ is determined by the international rate of interest $\bar{r}_{t}$. Hence the wage rate (price of one unit of human capital), $w_{t}=F_{L}\left(K_{t} / H_{t}, 1\right)$, is also determined once $\bar{r}_{t}$ is given.

\subsection{Financing Regime I}

Let us consider the decision problem that each $i \in G_{t}$ faces under Regime I, given $\bar{r}_{t}, w_{t}$, and $H_{t-1}$. At date $t-1$, when 'young', this individual chooses investment in education, $x^{i}$, while his ability is still unknown. The investment decision will be based on the noisy information about the agent's ability that is conveyed by the signal $y^{i}$. The investment, $x^{i}$, is financed through a standard loan contract which is signed at date $t-1$, and which involves the obligation to pay back $R_{t} x^{i}$ in period $t$.

\footnotetext{
${ }^{5}$ This assumption is in line with some implications of the globalization process that we have witnessed in recent decades. While globalization has increased the international mobility of physical capital tremendously, movements of labor across international borders are still the exception rather than the rule.
} 
An optimal decision is taken in two consecutive steps. At date $t-1$, after the signal $y^{i}$ has been observed, our agent $i \in G_{t}$ chooses an optimal level of investment in education, $x^{i}$, and signs the associated loan contract. When choosing the investment level, the agent perceives his ability to be randomly distributed according to $\nu_{y^{i}}(\cdot)$. Optimal savings, $s^{i}$, are chosen at date $t$ after ability, $A^{i}$, has been observed. At this time, $x^{i}$ (which has been chosen at date $t-1$ ) is predetermined.

For given levels of $h^{i}, x^{i}, w_{t}, R_{t}$, and $R_{t+1}$ the optimal consumption and saving decision is determined by

$$
\begin{aligned}
\max _{c_{1}^{i}, c_{2}^{i}, s^{i}} u_{1}\left(c_{1}^{i}\right)+u_{2}\left(c_{2}^{i}\right) \\
\text { s.t. } c_{1}^{i}=w_{t} h^{i}-R_{t} x^{i}-s^{i} \\
c_{2}^{i}=R_{t+1} s^{i} .
\end{aligned}
$$

Optimal savings satisfy the necessary and sufficient first order condition

$$
u_{1}^{\prime}\left(w_{t} h^{i}-R_{t} x^{i}-s^{i}\right)=R_{t+1} u_{2}^{\prime}\left(R_{t+1} s^{i}\right), \quad \forall A^{i} .
$$

The optimal level of investment in education is determined by (we mark random variables by $\mathrm{a}^{\sim}$ )

$$
\begin{array}{rl}
\max _{x^{i}} & E\left[u_{1}\left(\tilde{c}_{1}^{i}\right)+u_{2}\left(\tilde{c}_{2}^{i}\right) \mid y^{i}\right] \\
\text { s.t. } & \tilde{c}_{1}^{i}=w_{t} \tilde{h}^{i}-R_{t} x^{i}-\tilde{s}^{i} \\
& \tilde{c}_{2}^{i}=R_{t+1} \tilde{s}^{i},
\end{array}
$$

where $\tilde{h}^{i}$ is given by equation (1) and $\tilde{s}^{i}$ satisfies equation (5). By the Envelope theorem and the strict concavity of the utility functions, this optimization problem has a unique solution determined by the first order condition

$$
E\left\{\left[w_{t} \tilde{A} g_{1}^{\prime}\left(x^{i}, H_{t-1}\right)-R_{t}\right] u_{1}^{\prime}\left(\tilde{c}_{1}^{i}\right) \mid y^{i}\right\}=0 .
$$


At date $t-1$, the members of $G_{t}$ differ only by the signals they have received. Therefore, all individuals in the same signal group, $G_{t}(y)$, choose the same investment level, denoted $x_{t}(y) .{ }^{6}$ The net income (gross income net of repayment of the loan) in the working period of individuals in $G_{t}(y)$ is

$$
I_{t}(A, y)=w_{t} A g\left(x_{t}(y), H_{t-1}\right)-R_{t} x_{t}(y)
$$

The aggregate stock of human capital at date $t$ can be expressed as

$$
H_{t}=\int_{Y} \bar{A}_{y} g\left(x_{t}(y), H_{t-1}\right) \mu(y) \mathrm{d} y .
$$

Using (10) in (5), we may write optimal savings as $s_{t}\left(I_{t}(A, y)\right)$. Optimal consumption levels in the second and third periods of life are denoted by $c_{t}^{1}\left(I_{t}(A, y)\right)$ and $c_{t}^{2}\left(I_{t}(A, y)\right)$, respectively. From (5) we derive $s_{t}^{\prime}\left(I_{t}\right) \in(0,1)$. Equations $(3)$ and (4) then imply $c_{t}^{1 \prime}\left(I_{t}\right) \in(0,1)$ and $c_{t}^{2 \prime}\left(I_{t}\right) \in\left(0, R_{t+1}\right)$. Our economy starts at date 0 with given initial stocks of physical capital, $K_{0}$, and human capital, $H_{0}$. The dynamic equilibrium describes the time path of factor prices, savings and consumption profiles as well as the evolution of the individual human capital stocks which depend on the investments in education of the young generations.

Definition 1 Given the international interest rates $\left(\bar{r}_{t}\right)$ and the initial stocks of human and physical capital $H_{0}$ and $K_{0}$, a competitive equilibrium consists of a sequence $\left\{\left(c_{1}^{i}, c_{2}^{i}, s^{i}, x^{i}\right)_{i \in G_{t}}\right\}_{t=1}^{\infty}$, and a sequence of wages $\left(w_{t}\right)_{t=1}^{\infty}$, such that: At each date $t, t=1,2, \ldots$,

(i) given $\bar{r}_{t}, H_{t-1}$, and $w_{t}$, the optimum for each $i \in G_{t}$ in problems (2)-(4) and (6)-(8) is given by $\left(c_{1}^{i}, c_{2}^{i}, s^{i}, x^{i}\right)$,

(ii) the aggregate stocks of human capital, $H_{t}$, satisfy (11),

(iii) the factor prices satisfy $w_{t}=F_{L}\left(K_{t} / H_{t}, 1\right)$ and $1+\bar{r}_{t}=F_{K}\left(K_{t} / H_{t}, 1\right)$.

\footnotetext{
${ }^{6} x_{t}(y)$ depends on $H_{t-1}$. For notational convenience, we have chosen not to include $H_{t-1}$ as an argument of the investment function. We shall apply this convention to all behavioral functions and maintain it when we turn to other financing regimes.
} 
Our comparative dynamics analysis assumes that competitive equilibria (under various regimes) start from the same initial stocks, $K_{0}, H_{0}$, and compares the allocations along these dynamic paths period by period. The above definition of equilibrium also applies (with minor and obvious modification), if the economy operates under one of the two financing schemes outlined below.

\subsection{Financing Regime II}

Next we analyze the behavior of young individuals when funds needed to finance investment in higher education take the form of 'insured loans'. Assume that the payback obligation of a loan is linked to an individual's future (gross) income: agents with higher incomes (i.e., higher abilities) have higher payback obligations. ${ }^{7}$ Clearly, such loan contracts provide insurance against uncertain income prospects which are due to random ability realizations. We shall consider a risk pooling program of education loans that includes all young individuals of a given generation and which requires no subsidization from the government. In particular, by assumption, the regular credit markets cannot be used for funding educational expenditures. Let $\bar{A}:=E \tilde{A}=\int_{\mathcal{A}} A \nu(A) \mathrm{d} A$. Furthermore, define (gross) income of agent $i \in G_{t}$ as $I_{g}^{i}:=w_{t} h^{i}$, and let $\bar{I}_{g}$ be the agent's unconditionally expected income. For each dollar loaned, agent $i$ in $G_{t}$ is obliged to pay back $R_{t} I_{g}^{i} / \bar{I}_{g}=R_{t} A^{i} / \bar{A}$ dollars in his working period, if his income turns out to be $I_{g}^{i}$ (and, hence, his ability is $A^{i}$ ). Note that the repayment per dollar loaned does not depend on the agent's investment decision; hence no moral hazard problem arises. Note also that agent $i$ 's expected payback, $R_{t} x^{i} \bar{A}_{y^{i}} / \bar{A}$, is increasing in the signal, i.e., the scheme 'penalizes' agents with high signals.

This financing scheme takes no account of the heterogeneity in ability prospects that is already revealed through the individual signals when investment and borrowing decisions are made. Thus, the scheme does not just provide insurance, but it rather combines insurance against the unrealized part of ability with crosssubsidization between classes of people in different signal groups.

\footnotetext{
${ }^{7}$ An example of income-dependent rate of interest on educational loans exists now at the US tax code: all interest payments related to student loans are tax deductible!
} 
Proceeding as in Section 2.1, the necessary and sufficient conditions for optimal savings and investment decisions are

$$
\begin{aligned}
u_{1}^{\prime}\left(w_{t} h^{i}-R_{t} x^{i} \frac{A^{i}}{\bar{A}}-s^{i}\right) & =R_{t+1} u_{2}^{\prime}\left(R_{t+1} s^{i}\right), \quad \forall A^{i} \\
\bar{A} g_{1}^{\prime}\left(x^{i}, H_{t-1}\right) & =\frac{R_{t}}{w_{t}} .
\end{aligned}
$$

(13) implies that all individuals will invest the same amount, regardless of the signal they have received, i.e., $x^{i}=\hat{x}_{t} \forall i \in G_{t}$. The investment decision is independent of the signal because, as the signal changes, the expected marginal gain from investing changes by exactly the same amount as the expected marginal cost of investing, thereby eliminating any incentive to adjust the investment level. To see this, observe that the expected marginal gain from investing is $w_{t} g_{1}^{\prime}\left(x^{i}, H_{t-1}\right) \bar{A}_{y^{i}}$, and the expected marginal cost of investing is $R_{t} \bar{A}_{y^{i}} / \bar{A}$. By (13), the signal does not affect the difference between these expressions so that, at the optimum, the incentives to invest are independent of the signal.

By (13), $\hat{x}_{t}$ also depends on $H_{t-1}$ and, by our assumptions, it is nondecreasing in $H_{t-1} \cdot{ }^{8}$ Due to the pooling of predictable future income differences across agents with different signals, coupled with the risk aversion assumption, the optimal investment in education $\hat{x}_{t}$ maximizes the expected lifetime net income prior to the revelation of the signal; namely, $\hat{x}_{t}$ solves

$$
\max _{x} E\left\{w_{t} \tilde{A} g\left(x, H_{t-1}\right)-R_{t} x \frac{\tilde{A}}{\bar{A}}\right\}
$$

and, hence, it is independent of $y$.

This finding comes as no surprise, because one can think of Regime II as an insurance scheme from the ex-ante point of view of agents, i.e., prior to any information about abilities being revealed. Since ex-ante all agents are identical, the scheme leads to everyone investing the same amount.

Net income in the working period of an agent in $G_{t}$ with ability $A$ is given by

$$
\hat{I}_{t}(A)=w_{t} A g\left(\hat{x}_{t}, H_{t-1}\right)-R_{t} \hat{x}_{t} \frac{A}{\bar{A}},
$$

\footnotetext{
${ }^{8}$ To ease notation we simply write $\hat{x}_{t}$ instead of $\hat{x}_{t}\left(H_{t-1}\right)$ unless the dependency on $H_{t-1}$ is explicitly needed.
} 
and the aggregate stock of human capital at date $t$ is

$$
\hat{H}_{t}=\bar{A} g\left(\hat{x}_{t}, H_{t-1}\right) \text {. }
$$

Using (15) in (12), we may write optimal savings as $\hat{s}_{t}\left(\hat{I}_{t}(A)\right)$.

\subsection{Financing Regime III}

We finally consider a further class of 'insured' loan contracts which specify different terms of repayment for individuals in different signal groups. Again, the payback obligation of a loan is linked to an agent's future income and, hence, his random ability, but the implied risk pooling is restricted to individuals in a given signal group. An agent $i$ in $G_{t}$ with signal $y^{i}$ who receives a loan to finance investment in education $x^{i}$ is obliged to pay back $R_{t} x^{i} I_{g}^{i} / E\left[\tilde{I}_{g}^{i} \mid y^{i}\right]=R_{t} x^{i} A^{i} / \bar{A}_{y^{i}}$ in his working period, if his income turns out to be $I_{g}^{i}$ (and, hence, his ability is $A^{i}$ ). This program of education loans allows risk sharing on fair terms within each signal group, but does not provide risk sharing, or cross-subsidization, among different signal groups. ${ }^{9}$ In particular, an agent's expected payback does not depend on his signal so that agents with high signals are not 'penalized'.

As before, this income-linked loan program does not require any funding from the government: The agency providing the loans pays a gross interest rate $R_{t}$ in the capital market which is just equal to the rate realized on total loans within each signal group, i.e., $\int_{\mathcal{A}} R_{t} \frac{A}{A_{y}} \nu_{y}(A) \mathrm{d} A=R_{t}$.

The necessary and sufficient conditions for optimal savings and investment decisions are

$$
\begin{aligned}
u_{1}^{\prime}\left(w_{t} h^{i}-R_{t} x^{i} \frac{A^{i}}{\bar{A}_{y^{i}}}-s^{i}\right) & =R_{t+1} u_{2}^{\prime}\left(R_{t+1} s^{i}\right), \quad \forall A^{i} \\
\bar{A}_{y^{i}} g_{1}^{\prime}\left(x^{i}, H_{t-1}\right) & =\frac{R_{t}}{w_{t}}, \quad \forall y^{i} .
\end{aligned}
$$

According to (18), optimal investment in education of agents in the signal group $G_{t}(y)$ depends on the signal only via the term $\bar{A}_{y}$. We may, therefore, express

\footnotetext{
${ }^{9}$ There exist real world examples where private fundings are based on grouping students either by universities (e.g., at Yale, Harvard, etc.) or by fields of career. Lleras (2004, p. 66) argues that such practice is justified because 'grouping students by fields reflects similarity in the risks and the expected returns within the same group'.
} 
individual investment as $\check{x}_{t}\left(\bar{A}_{y}\right)$. Again, our notation suppresses the dependence of investment on $H_{t-1}$. From (18) we see that $\check{x}_{t}\left(\bar{A}_{y}\right)$ maximizes the expected conditional net income $\bar{A}_{y} w_{t} g\left(x, H_{t-1}\right)-R_{t} x$.

Since $g(x, H)$ is concave in $x$ and since $\bar{A}_{y}$ is increasing in $y$ (due to MLRP), equation (18) implies

Lemma 1 Optimal investment in education under Financing Regime III, $\check{x}_{t}(\cdot)$, is increasing in the signal $y$, and non-decreasing in $H_{t-1}$.

Thus, good news (higher signal) stimulates investment in education. Net income in the working period of an agent in $G_{t}$ with ability $A$ is given by

$$
\check{I}_{t}\left(A, \bar{A}_{y}\right)=w_{t} A g\left(\check{x}_{t}\left(\bar{A}_{y}\right), H_{t-1}\right)-R_{t} \check{x}_{t}\left(\bar{A}_{y}\right) \frac{A}{\bar{A}_{y}},
$$

and the aggregate stock of human capital at date $t$ is

$$
\check{H}_{t}=\int_{Y} \bar{A}_{y} g\left(\check{x}_{t}\left(\bar{A}_{y}\right), H_{t-1}\right) \mu(y) \mathrm{d} y .
$$

Using (19) in (17), we may write optimal savings as $\check{s}_{t}\left(\check{I}_{t}\left(A, \bar{A}_{y}\right)\right)$.

\section{Human Capital Accumulation}

In this section we compare the implications of the three financing schemes of educational investment for the equilibrium accumulation of human capital. The financing schemes involve different degrees of risk sharing in the economy. It is well known from the literature that an investor may invest more funds into a risky project, if, due to effective risk sharing arrangements, he can insure part of the project risk on easy terms. On the other hand, more effective insurance mechanisms also have the potential of destroying incentives for some agents to properly invest in education. The role of the various financing schemes for investment in education and human capital accumulation therefore deserves close scrutiny.

\section{Proposition 1 In equilibrium, ${ }^{10}$}

\footnotetext{
${ }^{10}$ The inequalities in (i) and (ii) are strict, if the conditional distribution of $\tilde{A}$ is non-degenerate for all signals $y$.
} 
(i) each agent chooses higher investment in education under Financing Regime III compared to Financing Regime $I: x_{t}(y) \leq \check{x}_{t}\left(\bar{A}_{y}\right)$ for all signals $y$;

(ii) the stock of human capital under Financing Regime III is larger than that under Financing Regime $I: \check{H}_{t} \geq H_{t} \quad$ for $t=1,2, \ldots$

This result demonstrates the critical role of risk pooling, which is restricted to signal groups. If such risk pooling takes place on conditionally fair terms, it enhances individual investment in education and, thereby, stimulates the formation of human capital, compared to non-insured funding via credit markets. The intuition for this finding is rather straightforward: the fact that under Regime III the agents' exposure to residual ability uncertainty is reduced through risk pooling leads them to invest more. ${ }^{11}$ Note, however, that there is no effort choice in our model. If income were affected by (unobservable) effort, then ability would no longer be perfectly observable through the income variable. In that case, risk pooling even within signal groups would create a disincentive to work and, consequently, Proposition 1 might no longer hold.

The comparison between Regime II (unconditional risk pooling) and Regime III (conditional risk pooling) is more intricate. While average investment in education may (but need not) be higher under Regime II than under Regime III, the latter regime always generates higher levels of aggregate human capital. To derive these results, we introduce the concepts of 'moderately decreasing concavity' and 'strongly decreasing concavity'. Let

$$
\hat{K}(x, H):=-\frac{g_{11}^{\prime \prime}(x, H)}{\left(g_{1}^{\prime}(x, H)\right)^{2}} \quad\left[=K(x, H) / g_{1}^{\prime}(x, H)\right] .
$$

$K(\cdot)$ and $\hat{K}(\cdot)$ are both (different) measures of concavity w.r.t. $x$ for the accumulation function $g(\cdot)$.

\footnotetext{
${ }^{11}$ It is worth pointing out, however, that a positive link between reduced uncertainty through risk pooling and investment activity is not a universal result. Sandmo (1971) showed in a different context that the marginal impact of uncertainty on a firm's investment decision, i.e., the effect of making a given distribution 'slightly more risky', is generally ambiguous. The overall effect, by contrast, which is the difference between the investment level under uncertainty and the investment level under certainty, is positive under standard assumptions.
} 
Definition 2 Given the restrictions formulated in Assumption 1, the accumulation function $g(x, H)$ exhibits

(i) moderately decreasing concavity, if $\hat{K}(x, H)$ is increasing in $x$.

(ii) strongly decreasing concavity, if $\hat{K}(x, H)$ is decreasing in $x$.

In order to illustrate these concepts let us focus for a moment on two classes of accumulation functions to which we will refer occasionally later on. The first class is the family of CRRA functions, and the second class is the family of CARA functions.

Case 1: Let $g(x, H): \mathbb{R}_{+}^{2} \rightarrow \mathbb{R}$ belong to the CRRA family, i.e.,

$$
g(x, H)=\frac{x^{1-\gamma}}{1-\gamma} H, \quad 0<\gamma<1
$$

Straightforward calculation shows that $K_{1}^{\prime}(x, H) \leq 0, \forall x, H$, i.e., the accumulation functions exhibit decreasing concavity. Furthermore, $\hat{K}(x, H)=\gamma x^{\gamma-1} / H$ is strictly decreasing in $x$, hence, the accumulation function exhibits strongly decreasing concavity.

Case 2: Let $g(x, H)$ belong to the CARA family, i.e.,

$$
g(x, H)=\left(1-e^{-\gamma x}\right) H, \quad \gamma>0
$$

In this case, $\hat{K}(x, H)=e^{\gamma x} / H, K(x)=\gamma$ and, hence, $g(x, H)$ exhibits moderately decreasing concavity.

Note that 'moderately decreasing concavity' and 'strongly decreasing concavity' are mutually exclusive properties. These properties are important because of their implications for the curvature of the investment function $\check{x}_{t}(\cdot)$ :

Lemma 2 The investment function $\check{x}_{t}\left(\bar{A}_{y}\right)$ under Regime III is concave (convex) in $\bar{A}_{y}$, if $g(x, H)$ exhibits moderately (strongly) decreasing concavity in $x$. 
Lemma 2 links the curvature of the accumulation function $g(\cdot)$ to the curvature of the investment function $\check{x}_{t}(\cdot)$. For the purpose of illustration, assume that $g(\cdot)$ exhibits moderately decreasing concavity. Such curvature implies (as compared to the case of strongly decreasing concavity) that the marginal return to investment decreases more rapidly. As a consequence, $x(\cdot)$ responds increasingly less sensitive to higher signals and, therefore, investment is concave.

Let aggregate investment in education at time $t$ under Regime I be $X_{t}:=$ $E\left[x_{t}(\tilde{y})\right]$. For regimes II and III, aggregate investments $\hat{X}_{t}$ and $\check{X}_{t}$ are defined analogously.

Proposition 2 In equilibrium,

(i) aggregate investment in education under Regime III is higher than under Regime II, i.e., $\check{X}_{t} \geq \hat{X}_{t}$ for all $t$, if the accumulation function $g(x, H)$ exhibits strongly decreasing concavity;

(ii) $\hat{X}_{t} \geq \check{X}_{t}$ holds for all $t$, if $g(x, H)$ is independent of $H$ and exhibits moderately decreasing concavity.

This result is quite surprising because the better talented agents subsidize the less talented ones more heavily under Regime II, where all risks are pooled, than under Regime III, where risks are pooled conditional on the signals. Yet, in the absence of adverse incentive effects, this sort of cross-subsidization affects the aggregate investment level only through the curvature of $\check{x}_{t}(\cdot)$. If the investment function is concave (convex) then investment chosen at the average signal - which is the investment level under Regime II - is higher (lower) than average investment under Regime III.

According to our next proposition, the financing regimes II and III can unambiguously be ranked with regard to their impact on human capital formation. Thus, in view of Proposition 1, higher investment in education is neither necessary nor sufficient for higher economic growth.

Proposition 3 The equilibrium aggregate human capital levels under Regime III are higher than those under Regime II at all dates: $\check{H}_{t} \geq \hat{H}_{t}$, for all $t$. 
Thus, the Financing Regime III is more efficient than Regime II in terms of generating economic growth. This result is quite surprising: we do expect, of course, that the same amount of aggregate investment will translate into more aggregate human capital under Regime III than under Regime II, because under the former regime agents use the signal information while under the latter regime the information is discarded. Proposition 2 makes the stronger (and less obvious) claim that this effect always dominates the higher level of aggregate investment which obtains in Regime II under moderately decreasing concavity of $g(\cdot)$.

The result in Proposition 1 is based on a simple economic mechanism. Since marginal returns to investment depend on individual abilities, the distribution of individual investments across agents with different abilities affects the formation of human capital in the economy. In particular, a financing regime that encourages investments of highly talented agents and discourages investments of poorly talented agents may achieve high levels of aggregate human capital with relatively low levels of aggregate investment in education. In fact, if $g(\cdot)$ is independent of $H$, this happens under moderately decreasing concavity of the accumulation function, when we switch from Regime II to Regime III. Under Regime II, investment in education is high but uncorrelated to individual ability. Under Regime III, by contrast, the better talented agents tend to invest more aggressively than the poorly talented agents. Since individual investments and abilities are better aligned (and, in this sense, the transformation of aggregate investment in education into aggregate human capital is more efficient) under Regime III than under Regime II, aggregate human capital levels are higher even though the economy as a whole may invest less in education.

\section{Welfare Implications}

Our welfare analysis of the various financing regimes will be based on an ex-ante welfare concept. Note that all agents of the same generation are identical ex ante, i.e., before their signals have realized. We therefore define economic welfare, $W_{t}$, of generation $G_{t}$ as the ex-ante expected utility of members of $G_{t}$. A financing regime $j$ will be ranked higher than a financing regime $k(j, k=\mathrm{I}, \mathrm{II}, \mathrm{III})$ if all generations attain higher welfare under Regime $j$ than under Regime $k$. 
Welfare of generation $G_{t}$ under Regime I is defined by

$$
W_{t}:=\int_{Y} V_{t}\left(y, H_{t-1}\right) \mu(y) \mathrm{d} y
$$

where

$$
V_{t}\left(y, H_{t-1}\right):=E\left[u_{1}\left(c_{t}^{1}(\tilde{A}, y)\right)+u_{2}\left(c_{t}^{2}\left(I_{t}(\tilde{A}, y)\right)\right) \mid y\right]
$$

$V_{t}\left(y, H_{t-1}\right)$, the value function for generation $G_{t}$, represents the conditional expected utility of a member of $G_{t}$ with signal $y$. Since $g\left(x, H_{t-1}\right)$ is increasing in $H_{t-1}$, the value function is also increasing in $H_{t-1}$. The value functions and welfare levels of generation $G_{t}$ under regimes II and III, $\hat{V}_{t}\left(y, \hat{H}_{t-1}\right), \check{V}_{t}\left(y, \check{H}_{t-1}\right)$ and $\hat{W}_{t}, \check{W}_{t}$, are defined symmetrically. We say that, e.g., welfare is higher under Regime III than under Regime II, if $\check{W}_{t} \geq \hat{W}_{t}$ holds for all $t \geq 1$.

Proposition 4 In equilibrium, economic welfare is higher under Regime III than under Regime I.

Thus, under any political voting process, if it were to be conducted prior to the revelation of signals, the arrangement of Regime III, which provides conditionally insured financing of private investment in education, will prevail against a regime of pure credit markets. Regime III leads to higher welfare, because the individuals benefit from partial risk pooling. This positive impact on welfare is not counteracted by adverse incentive effects which might result from partial risk sharing: since risks are only shared within signal groups, the signal risk remains uninsured. Therefore, the incentive structure remains intact and all agents continue to take their signals into account when choosing investment in education.

Next we turn to a comparison of economic welfare under regimes II and III. Under Regime III aggregate human capital is accumulated more efficiently because agents take their signals into account when deciding about investment in education: agents with good signals who are, on average, better talented invest more than agents with bad signals. Under Regime II, by contrast, everybody invests the same amount regardless of the signal. On the other hand, Regime II provides better pooling of individual income risks than Regime III. To illustrate the interaction 
between economic efficiency and risk sharing we specialize our economy by choosing the following functional forms:

$$
u_{1}(c)=\frac{c^{1-\beta}}{1-\beta} ; \quad u_{2}(c)=\delta \frac{c^{1-\beta}}{1-\beta} ; \quad g(x)=\frac{x^{1-\gamma}}{1-\gamma},
$$

where $\gamma \in\left(0, \frac{1}{2}\right)$ and $1 \neq \beta>0$. Note that the specification in (23) implies that $g(\cdot)$ depends only on investment in education, but not on the human capital stock of the previous generation. The main implication of this simplification is that optimal individual investment in education no longer depends on the human capital stock of the earlier generation.

For some suitably chosen $m \in(0,1)$ optimal consumption under Regime III can be stated as ${ }^{12}$

$$
\begin{gathered}
\check{c}_{t}^{1}=\frac{A \gamma(1-m)}{1-\gamma} w_{t}^{1 / \gamma}\left(\frac{\bar{A}_{y}}{R_{t}}\right)^{\frac{1-\gamma}{\gamma}} \\
c_{t}^{2}=\frac{A R_{t+1} \gamma m}{1-\gamma} w_{t}^{1 / \gamma}\left(\frac{\bar{A}_{y}}{R_{t}}\right)^{\frac{1-\gamma}{\gamma}} .
\end{gathered}
$$

From the last two equations we derive the value function $\check{V}_{t}(\cdot)$ which satisfies

$$
\frac{1-\beta}{M_{t}} \check{V}_{t}(y)=E\left[\tilde{A}^{1-\beta} \mid y\right]\left(\frac{\bar{A}_{y}}{R_{t}}\right)^{\frac{(1-\gamma)(1-\beta)}{\gamma}},
$$

where $M_{t}:=\left[\gamma w_{t}^{1 / \gamma} /(1-\gamma)\right]^{1-\beta}\left[(1-m)^{1-\beta}+\delta\left(R_{t+1} m\right)^{1-\beta}\right]$ is a positive constant.

Similarly, the value function for Regime II satisfies

$$
\frac{1-\beta}{M_{t}} \hat{V}_{t}(y)=E\left[\tilde{A}^{1-\beta} \mid y\right]\left(\frac{\bar{A}}{R_{t}}\right)^{\frac{(1-\gamma)(1-\beta)}{\gamma}} .
$$

Proposition 5 Assume that the utility functions and the human capital formation function are of the type specified in (23).

\footnotetext{
${ }^{12} \mathrm{~m}$ represents the saving propensity out of net income, which is constant under the above specification.
} 
(i) If the measure of relative risk aversion, $\beta$, is larger than 1 , then economic welfare under Regime II is higher than under Regime III.

(ii) If $\beta \leq(1-2 \gamma) /(1-\gamma)$, then economic welfare under Regime II is lower than under Regime III.

In Section 3, we have seen that individual investments and individual abilities are better aligned and, therefore, the allocation of investment in education is more efficient under Regime III than under Regime II. Nevertheless, according to Proposition 5(i) all agents may be better off under Regime II. This result can be reconciled with economic intuition once we realize that economic welfare depends not only on the efficiency of the human capital accumulation process, but also on the equilibrium risk allocation. Under Regime II individual ability risks are better insured, while under Regime III investment is more efficiently transformed into human capital. According to Proposition 5 the former effect is dominant in terms of economic welfare, if the individuals are highly risk-averse; and the latter effect is dominant if individuals are moderately risk-averse, i.e., if the measure of relative risk aversion is sufficiently small.

Proposition 5 has been derived under the assumption that the capital formation function $g(\cdot)$ is independent of $H$. If, under a more general specification, $g(\cdot)$ is an increasing function of $H$, the welfare comparison between regimes II and III shifts in favor of Regime III: In view of Proposition 3, aggregate human capital levels are higher under Regime III than under Regime II. Therefore, since under any regime the value function of generation $G_{t}$ is increasing in the human capital stock of $G_{t-1}$, the second part of Proposition 5 remains valid (and can even be strengthened). By contrast, the first part of Proposition 5, which claims that welfare under Regime II can be higher than welfare under Regime III, may no longer hold, if the previous generation's capital stock exerts a strong externality on capital formation in the current period. 


\section{Conclusion}

The incentives of individuals to invest in higher education are affected by the financing scheme under which educational loans are available to them. In this paper we have analyzed and compared the implications of three different funding regimes. The regimes differ with regard to the terms of repayment of educational loans. In particular, the extent to which the payback obligations are contingent on the individuals' future incomes plays a critical role. While all regimes are self-financing, i.e., they do not require government subsidies, some government intervention is necessary in order to make the funding mechanisms operative. The first regime works via competitive credit markets. The role of the government is to ensure that students have unrestricted access to those markets and to enforce debt collection. The second regime pools the income risks of all agents in the same generation and treats them equally, i.e, it imposes the same income-dependent payback obligations on all individuals. This regime cannot be decentralized but must be implemented by the government. The third regime pools income risks within each signal group (partial risk pooling). All agents in the same signal group are treated equally, but individuals with good signals receive loans on more favorable (income-contingent) terms than agents with bad signals.

We have studied these three financing regimes under the assumption that the same regime applies to all agents. In particular, agents are not free to choose a repayment scheme that looks most attractive to them. This specification constitutes an important limitation for the generality of our model. Of course, in a more general setting several financing schemes might coexist at the same time so that in equilibrium agents self-select into different groups according to the repayment schemes they prefer. This possibility is excluded in our analysis and may be the topic of future research.

We found that aggregate investment in education and human capital stocks are higher under Regime III compared with Regime I, i.e., partial pooling of income risks stimulates economic growth. By contrast, unrestricted risk pooling causes efficiency losses: investment in education is more efficiently transformed into human capital under Regime III compared with Regime II. Finally, Regime III leads to higher welfare than Regime I. And the welfare comparison between regimes II and III 
depends on the individuals' attitudes towards risk: Regime III generates higher (lower) welfare than Regime II, if the measure of relative risk aversion is sufficiently small (high). This result reflects the interaction of two mechanisms resulting from the fact that income risks are better pooled under Regime II, while the process which transforms educational investment into human capital is more efficient under Regime III.

The main purpose of our study was to compare Regime I (competitive credit markets) with Regime III (partial risk pooling), because these regimes are implementable in a decentralized setting. Our analysis yields a clear and unambiguous policy recommendation in favor of Regime III which generates higher growth as well as higher welfare than Regime I.

Our model also has implications with regard to income inequality under the various financing schemes for higher education. These implications have not been reported here. Based on a standard concept of income dispersion, it can be shown that, not surprisingly, Regime II leads to a more egalitarian income distribution than any of the two other regimes.

\section{Appendix}

Proof of Proposition 1: (i) Under scheme I, individuals have access to loans provided by the banks at the market interest rates $R_{t}$. For each given $y$ and fixed $H_{t-1}$ we have,

$$
\operatorname{Cov}\left[(\tilde{A} \mid y), u_{1}^{\prime}\left(c_{t}^{1}(\tilde{A}, y)\right)\right] \leq 0
$$

The covariance in (26) is non-positive, since $c_{t}^{1}(A, y)$ is increasing in $A$. From equation (9) and equation (26) we derive $E\left[w_{t} g_{1}^{\prime}\left(x_{t}(y), H_{t-1}\right) \tilde{A}-R_{t} \mid y\right] \geq 0$ which implies

$$
g_{1}^{\prime}\left(x_{t}(y), H_{t-1}\right) \bar{A}_{y} \geq \frac{R_{t}}{w_{t}}
$$

Combining (18) and (27), and making use of the concavity of $g(x, H)$ in $x$, we 
conclude that $x_{t}(y) \leq \check{x}_{t}\left(\bar{A}_{y}\right)$.

(ii) The proof is by induction over time periods $t=1,2, \cdots$. Since $K_{0}, H_{0}$ are given at the outset, part (i) implies $\check{H}_{1} \geq H_{1}$. Assume $\check{H}_{t^{\prime}} \geq H_{t^{\prime}}$ for all $t^{\prime} \leq t$. Since, by assumption, $g_{1}^{\prime}(x, H)$ is non-decreasing in $H, g_{1}^{\prime}\left(x_{t+1}(y), \check{H}_{t}\right) \bar{A}_{y} \geq$ $g_{1}^{\prime}\left(x_{t+1}(y), H_{t}\right) \bar{A}_{y} \geq \frac{R_{t+1}}{w_{t+1}}$ and $g_{1}^{\prime}\left(\check{x}_{t+1}\left(\bar{A}_{y}\right), \check{H}_{t}\right) \bar{A}_{y}=\frac{R_{t+1}}{w_{t+1}}$ are satisfied. Thus, $x_{t+1}(y) \leq \check{x}_{t+1}\left(\bar{A}_{y}\right)$ holds for each individual in generation $G_{t+1}$ with signal $y$. Integrating over all signals yields $H_{t+1} \leq \check{H}_{t+1}$.

Proof of Lemma 2: Differentiating (18), we obtain

$$
\frac{\partial \check{x}_{t}\left(\bar{A}_{y}\right)}{\partial \bar{A}_{y}}=\frac{w_{t}}{\hat{K}\left(\check{x}_{t}(\cdot), \check{H}_{t-1}\right) R_{t}} .
$$

$\check{x}_{t}(\cdot)$ is increasing in $\bar{A}_{y}$ according to $(18)$. Therefore, $\check{x}_{t}(\cdot)$ is concave (convex) in $\bar{A}_{y}$, if $g(x, H)$ exhibits moderately (strongly) decreasing concavity in $x$.

Proof of Proposition 2: (i) Since $g(\cdot)$ exhibits strongly decreasing concavity, $\check{x}_{t}(\cdot)$ is convex in $\bar{A}_{y}$ according to Lemma 2 . Then, (13) and (18) imply $\hat{x}_{t}=\check{x}_{t}(\bar{A})$. Proposition 3 claims (and proves independently of this proposition) that $\check{H}_{t-1} \geq$ $\hat{H}_{t-1}$. Using this fact along with monotonicity of $\check{x}_{t}$ in $\check{H}_{t-1}$ and convexity in $\bar{A}_{y}$, we conclude

$$
\check{X}_{t}=E\left[\check{x}_{t}\left(\bar{A}_{\tilde{y}}, \check{H}_{t-1}\right)\right] \geq \check{x}_{t}\left(\bar{A}, \check{H}_{t-1}\right) \geq \check{x}_{t}\left(\bar{A}, \hat{H}_{t-1}\right)=\hat{x}_{t}\left(\hat{H}_{t-1}\right)=\hat{X}_{t} .
$$

(ii) Under this restriction on the functional form of $g(\cdot), \check{x}_{t}(\cdot)$ is independent of $\check{H}_{t-1}$ and concave in $\bar{A}_{y}$. The inequality signs in (28) are thus all reversed which proves the claim.

Proof of Proposition 3: The proof consists of two steps.

(i) Let $\bar{h}\left(z, H_{t-1}\right):=z g\left(\check{x}_{t}(z), H_{t-1}\right)$. In a first step we show that $\bar{h}\left(z, H_{t-1}\right)$ is convex in $z$. Differentiating $\bar{h}(\cdot)$ with respect to $z$ and using equation (18), we get

$$
\bar{h}_{11}^{\prime \prime}\left(z, H_{t-1}\right)=\frac{R_{t} \check{x}_{t}^{\prime}(z)}{w_{t} z}\left[1+\frac{\check{x}_{t}^{\prime \prime}(z) z}{\check{x}_{t}^{\prime}(z)}\right]
$$


From (18) we calculate the elasticity of the investment function as

$$
\frac{\check{x}_{t}^{\prime \prime}(z) z}{\check{x}_{t}^{\prime}(z)}=-\left(1+\frac{K_{1}^{\prime}\left(\check{x}_{t}(z), H_{t-1}\right)}{\left[K\left(\check{x}_{t}(z), H_{t-1}\right)\right]^{2}}\right) .
$$

Combining the last two equations we obtain

$$
\bar{h}_{11}^{\prime \prime}\left(z, H_{t-1}\right)=-\frac{K_{1}^{\prime}\left(\check{x}_{t}(z), H_{t-1}\right) / z}{\left[K\left(\check{x}_{t}(z), H_{t-1}\right)\right]^{2} \hat{K}\left(\check{x}_{t}(z), H_{t-1}\right)} .
$$

By Assumption 1, $K_{1}^{\prime}(\cdot)$ is non-positive and, hence, $\bar{h}(\cdot)$ is convex in $z$.

(ii) Now we can prove the claim of the proposition by an induction argument. Assume $\check{H}_{t^{\prime}-1} \geq \hat{H}_{t^{\prime}-1}$ for $t^{\prime} \leq t$. We conclude that

$$
\check{H}_{t}=E\left[\bar{h}\left(\bar{A}_{\tilde{y}}, \check{H}_{t-1}\right)\right] \geq \bar{h}\left(\bar{A}, \check{H}_{t-1}\right)=\bar{A} g\left(\check{x}_{t}(\bar{A}), \check{H}_{t-1}\right) \geq \bar{A} g\left(\hat{x}_{t}, \hat{H}_{t-1}\right)=\hat{H}_{t},
$$

where the first inequality follows from step (i), and the second inequality follows from the induction hypothesis in conjunction with Lemma 1.

Proof of Proposition 4: We show that $\check{V}_{t}\left(y, \check{H}_{t-1}\right) \geq V_{t}\left(y, H_{t-1}\right)$ holds for all $y$ and any fixed $t$, from which the claim in the proposition follows immediately. From Proposition 1 we know that $\check{H}_{t-1} \geq H_{t-1}$. Therefore, since $\check{V}(\cdot)$ is increasing in the second argument, it is sufficient to show that $\check{V}_{t}\left(y, H_{t-1}\right) \geq V_{t}\left(y, H_{t-1}\right) \forall y$ is satisfied. Optimal consumption decisions under Regime I are given by

$$
\begin{aligned}
c_{t}^{1}(A, y) & =\left[w_{t} g\left(x_{t}(y), H_{t-1}\right) A-s_{t}\left(I_{t}(A, y)\right)\right]-R_{t} x_{t}(y) \\
c_{t}^{2}\left(I_{t}(A, y)\right) & =R_{t+1} s_{t}\left(I_{t}(A, y)\right),
\end{aligned}
$$

where net income $I_{t}(\cdot)$ has been defined in $(10)$. The value function is

$$
V_{t}\left(y, H_{t-1}\right)=E\left\{u_{1}\left(c_{t}^{1}(\tilde{A}, y)\right)+u_{2}\left(c_{t}^{2}\left(I_{t}(\tilde{A}, y)\right)\right) \mid y\right\}
$$

If we set $\check{H}_{t-1}=H_{t-1}$ (as argued above) and denote by $\bar{s}_{t}(y):=E\left[s_{t}\left(I_{t}(\tilde{A}, y)\right)\right]$ average savings conditional on the signal $y$, then under Regime III the following $~$ -allocation is admissible (but not necessarily optimal): 


$$
\begin{aligned}
\breve{x}_{t}(y) & =x_{t}(y) \\
\breve{s}_{t}(A, y) & =s_{t}\left(I_{t}(A, y)\right)\left[1-\frac{R_{t} x_{t}(y)}{w_{t} \bar{A}_{y} g\left(x_{t}(y), H_{t-1}\right)}\right]+R_{t} x_{t}(y) \frac{\bar{s}_{t}(y)}{w_{t} \bar{A}_{y} g\left(x_{t}(y), H_{t-1}\right)} \\
\breve{c}_{t}^{1}(A, y) & =\left[1-\frac{R_{t} x_{t}(y)}{w_{t} \bar{A}_{y} g\left(x_{t}(y), H_{t-1}\right)}\right]\left[w_{t} g\left(x_{t}(y), H_{t-1}\right) A-s_{t}\left(I_{t}(A, y)\right)\right] \\
& -R_{t} x_{t}(y) \frac{\bar{s}_{t}(y)}{w_{t} g\left(x_{t}(y), H_{t-1}\right) \bar{A}_{y}} \\
\breve{c}_{t}^{2}(A, y) & =R_{t+1} \breve{s}_{t}(A, y)
\end{aligned}
$$

To complete the proof we show that the $\backsim$-decision leads to higher expected utility conditional on $y$ than the optimal decision under Regime 1. From (29) and (30) it is immediate that $E\left\{\breve{c}_{t}^{1}(\tilde{A}, y) \mid y\right\}=E\left\{c_{t}^{1}(\tilde{A}, y) \mid y\right\}$. Also, $\left[w_{t} g\left(x_{t}(y), H_{t-1}\right) A-\right.$ $\left.s_{t}\left(I_{t}(A, y)\right)\right]$ is increasing in $A$ (see equation (5)). Thus, $c_{t}^{1}(\tilde{A}, y)$ differs from $\breve{c}_{t}^{1}(\tilde{A}, y)$ by a mean preserving spread which implies $E\left\{u_{1}\left(\breve{c}_{t}^{1}(\tilde{A}, y)\right) \mid y\right\} \geq E\left\{u_{1}\left(c_{t}^{1}(\tilde{A}, y)\right) \mid y\right\}$. Similarly, $E\left\{u_{2}\left(\breve{c}_{t}^{2}(\tilde{A}, y)\right) \mid y\right\} \geq E\left\{u_{2}\left(c_{t}^{2}\left(I_{t}(\tilde{A}, y)\right) \mid y\right\}\right.$ because $s_{t}\left(I_{t}(\tilde{A}, y)\right)$ is a mean preserving spread of $\breve{s}_{t}(\tilde{A}, y)$. We have shown that $\check{V}_{t}\left(y, H_{t-1}\right) \geq V_{t}\left(y, H_{t-1}\right)$.

Proof of Proposition 5: (i) For $\beta>1,\left(\bar{A}_{y} / R_{t}\right)^{(1-\gamma)(1-\beta) / \gamma}$ is a convex function of $\bar{A}_{y}$, which is positively correlated with $E\left[\tilde{A}^{1-\beta} \mid y\right]$. The representations in (24) and (25) therefore imply the following assessment:

$$
\begin{aligned}
\frac{1-\beta}{M_{t}} \check{W}_{t} & =\frac{1-\beta}{M_{t}} E\left[\check{V}_{t}(\tilde{y})\right]>E\left[\tilde{A}^{1-\beta}\right] E\left[\left(\frac{\bar{A}_{\tilde{y}}}{R_{t}}\right)^{\frac{(1-\gamma)(1-\beta)}{\gamma}}\right] \\
& >E\left[\tilde{A}^{1-\beta}\right]\left(\frac{\bar{A}}{R_{t}}\right)^{\frac{(1-\gamma)(1-\beta)}{\gamma}}=\frac{1-\beta}{M_{t}} E\left[\hat{V}_{t}(\tilde{y})\right]=\frac{1-\beta}{M_{t}} \hat{W}_{t} .
\end{aligned}
$$

Since $(1-\beta)$ is negative, $\check{W}_{t}<\hat{W}_{t}, t \geq 1$, follows. 
(ii) Under this specification, $\left(\bar{A}_{y} / R_{t}\right)^{(1-\gamma)(1-\beta) / \gamma}$ is again a convex function of $\bar{A}_{y}$ which is positively correlated with $E\left[\tilde{A}^{1-\beta} \mid y\right]$. The same assessment as under (i) therefore yields $\check{W}_{t}>\hat{W}_{t}$ since now $(1-\beta)$ is positive.

\section{References}

Albrecht, D., Ziderman, A.: Student Loans: An Effective Instrument for Cost Recovery in Higher Education? The World Bank Research Observer 8(1), 71-90 (1993).

Azariadis, C., Drazen, A.: Threshold Externalities in Economic Development. Quarterly Journal of Economics 105, 501-526 (1990).

Barr, N., Crawford, I.: Funding Higher Education in an Age of Expansion. Education Economics 6(1), 45-70 (1998).

Barro, R.: The Determinants of Economic Growth. Cambridge, MA: MIT Press (1998).

Bassanini, S., Scarpenta, S.: Does Human Capital Matter for Growth in OECD Countries? Evidence form pooled mean-group estimates. OECD Economics Department, WP \# 282, Paris (2001).

Checchi, D.: The Economics of Education, Cambridge: Cambridge University Press (2006).

Feldman, M., Gilles, C.: An Expository Note on Individual Risk without Aggregate Uncertainty. Journal of Economic Theory 35, 26-32 (1985).

Friedman, M.: The Role of Government in Education in R.A. Solow (ed.). Economics and the Public Interest, Piscataway, Rutgers University Press (1955).

Friedman, M.: Capitalism and Freedom. Chicago: University of Chicago Press (1962).

Galor, O., Zeira, J.: Income Distribution and Macroeconomics. Review of Economic Studies 60, 35-52 (1993). 
Greenaway, D., Haynes, M.: Funding Higher Education in the UK: The role of Fees and Loans. The Economic Journal 113 (February), F150-F166 (2003).

Kaganovich, M.: Education Reform and Access to Public Education in Russia. Department of Economics, Indiana University, Manuscript (2005).

Lleras, M.P.: Investing in Human Capital. Cambridge University Press: Cambridge, UK (2004).

Milgrom, P. R.: Good News and Bad News: Representation Theorems and Applications. Bell Journal of Economics 12, 380-391 (1981).

Orazem, P., Tesfatsion, L.: Macrodynamic Implications of Income-Transfer Policies for Human Capital Investment and School Effort. Journal of Economic Growth 2, 305-329 (1997).

Restuccia D., Urrutia, C.: Intergenerational Persistence of Earnings: The Role of Early and College Education. American Economic Review 94, 1354-1378 (2004).

Sandmo, A.: On the Theory of the Competitive Firm Under Price Uncertainty. American Economic Review 61(1), 65-73 (1971).

Viaene, J.M., Zilcha, I.: Capital Markets Integration, Growth and Income Distribution. European Economic Review 46, 301-327 (2002).

Woodhall, M.: Designing a Student Loan Programme for a Developing Country: the Relevance of International Experience. Economics of Education Review 7(1), 153-161 (1988). 


\section{CESifo Working Paper Series}

for full list see www.cesifo-group.org/wp

(address: Poschingerstr. 5, 81679 Munich, Germany, office@cesifo.de)

2333 Erkki Koskela and Panu Poutvaara, Outsourcing and Labor Taxation in Dual Labor Markets, June 2008

2334 Philippe Choné and Laurent Linnemer, Optimal Litigation Strategies with Signaling and Screening, June 2008

2335 Albert Solé-Ollé and Pilar Sorribas-Navarro, Does Partisan Alignment Affect the Electoral Reward of Intergovernmental Transfers?, June 2008

2336 Antonio Cabrales and Piero Gottardi, Markets for Information: Of Inefficient Firewalls and Efficient Monopolies, June 2008

2337 Sumon Majumdar and Sharun W. Mukand, The Leader as Catalyst - on Leadership and the Mechanics of Institutional Change, June 2008

2338 Ulrich Hange, Tax Competition, Elastic Labor Supply, and Growth, June 2008

2339 Guy Laroque and Bernard Salanié, Does Fertility Respond to Financial Incentives?, June 2008

2340 Adriano Paggiaro, Enrico Rettore and Ugo Trivellato, The Effect of Extending the Duration of Eligibility in an Italian Labour Market Programme for Dismissed Workers, June 2008

2341 Helmut Seitz, Minimum Standards, Fixed Costs and Taxing Autonomy of Subnational Governments, June 2008

2342 Robert S. Chirinko, Leo de Haan and Elmer Sterken, Asset Price Shocks, Real Expenditures, and Financial Structure: A Multi-Country Analysis, July 2008

2343 Wolfgang Leininger, Evolutionarily Stable Preferences in Contests, July 2008

2344 Hartmut Egger and Udo Kreickemeier, Fairness, Trade, and Inequality, July 2008

2345 Ngo Van Long and Bodhisattva Sengupta, Yardstick Competition, Corruption, and Electoral Incentives, July 2008

2346 Florian Baumann, Employment Protection: The Case of Limited Enforceability, July 2008

2347 Alessandro Balestrino, Cinzia Ciardi and Claudio Mammini, On the Causes and Consequences of Divorce, July 2008

2348 Dirk Schindler and Benjamin Weigert, Insuring Educational Risk: Opportunities versus Income, July 2008 
2349 Lammertjan Dam and Ben J. Heijdra, The Environmental and Macroeconomic Effects of Socially Responsible Investment, July 2008

2350 Avner Greif, Contract Enforcement and Institutions among the Maghribi Traders: Refuting Edwards and Ogilvie, July 2008

2351 Helmuth Cremer, Philippe De Donder, Dario Maldonado and Pierre Pestieau, Habit Formation and Labor Supply, July 2008

2352 Francesco Menoncin and Paolo M. Panteghini, The Johansson-Samuelson Theorem in General Equilibrium: A Rebuttal, July 2008

2353 Michael Kaganovich and Itzhak Zilcha, Alternative Social Security Systems and Growth, July 2008

2354 Keith Blackburn, Kyriakos C. Neanidis and M. Emranul Haque, Corruption, Seigniorage and Growth: Theory and Evidence, July 2008

2355 Edward Castronova, A Test of the Law of Demand in a Virtual World: Exploring the Petri Dish Approach to Social Science, July 2008

2356 Harald Badinger and Peter Egger, GM Estimation of Higher-Order Spatial Autoregressive Processes in Cross-Section Models with Heteroskedastic Disturbances, July 2008

2357 Wolfgang Buchholz and Jan Schumacher, Discounting the Long-Distant Future: A Simple Explanation for the Weitzman-Gollier-Puzzle, July 2008

2358 Luca Anderlini, Leonardo Felli and Alessandro Riboni, Statute Law or Case Law?, July 2008

2359 Guglielmo Maria Caporale, Davide Ciferri and Alessandro Girardi, Are the Baltic Countries Ready to Adopt the Euro? A Generalised Purchasing Power Parity Approach, July 2008

2360 Erkki Koskela and Ronnie Schöb, Outsourcing of Unionized Firms and the Impacts of Labour Market Policy Reforms, July 2008

2361 Francisco Alvarez-Cuadrado and Ngo Van Long, A Permanent Income Version of the Relative Income Hypothesis, July 2008

2362 Gabrielle Demange, Robert Fenge and Silke Uebelmesser, Financing Higher Education and Labor Mobility, July 2008

2363 Alessandra Casarico and Alessandro Sommacal, Labor Income Taxation, Human Capital and Growth: The Role of Child Care, August 2008

2364 Antonis Adam, Manthos D. Delis and Pantelis Kammas, Fiscal Decentralization and Public Sector Efficiency: Evidence from OECD Countries, August 2008 
2365 Stefan Voigt, The (Economic) Effects of Lay Participation in Courts - A Cross-Country Analysis, August 2008

2366 Tobias König and Andreas Wagener, (Post-)Materialist Attitudes and the Mix of Capital and Labour Taxation, August 2008

2367 Ximing Wu, Andreas Savvides and Thanasis Stengos, The Global Joint Distribution of Income and Health, August 2008

2368 Alejandro Donado and Klaus Wälde, Trade Unions Go Global!, August 2008

2369 Hans Gersbach and Hans Haller, Exit and Power in General Equilibrium, August 2008

2370 Jan P.A.M. Jacobs and Jan-Egbert Sturm, The Information Content of KOF Indicators on Swiss Current Account Data Revisions, August 2008

2371 Oliver Hülsewig, Johannes Mayr and Timo Wollmershäuser, Forecasting Euro Area Real GDP: Optimal Pooling of Information, August 2008

2372 Tigran Poghosyan and Jakob de Haan, Determinants of Cross-Border Bank Acquisitions in Transition Economies: A Latent Class Analysis, August 2008

2373 David Anthoff and Richard S.J. Tol, On International Equity Weights and National Decision Making on Climate Change, August 2008

2374 Florian Englmaier and Arno Schmöller, Reserve Price Formation in Online Auctions, August 2008

2375 Karl Farmer, Birgit Friedl and Andreas Rainer, Effects of Unilateral Climate Policy on Terms of Trade, Capital Accumulation, and Welfare in a World Economy, August 2008

2376 Monika Bütler, Stefan Staubli and Maria Grazia Zito, The Role of the Annuity’s Value on the Decision (Not) to Annuitize: Evidence from a Large Policy Change, August 2008

2377 Inmaculada Martínez-Zarzoso, The Impact of Urbanization on $\mathrm{CO}_{2}$ Emissions: Evidence from Developing Countries, August 2008

2378 Brian Roberson and Dmitriy Kvasov, The Non-Constant-Sum Colonel Blotto Game, August 2008

2379 Ian Dew-Becker, How Much Sunlight Does it Take to Disinfect a Boardroom? A Short History of Executive Compensation Regulation, August 2008

2380 Cécile Aubert, Oliver Falck and Stephan Heblich, Subsidizing National Champions: An Evolutionary Perspective, August 2008

2381 Sebastian Buhai, Miguel Portela, Coen Teulings and Aico van Vuuren, Returns to Tenure or Seniority?, August 2008 
2382 Erkki Koskela and Jan König, Flexible Outsourcing, Profit Sharing and Equilibrium Unemployment, August 2008

2383 Torberg Falch and Justina AV Fischer, Does a Generous Welfare State Crowd out Student Achievement? Panel Data Evidence from International Student Tests, September 2008

2384 Pedro Gomes and François Pouget, Corporate Tax Competition and the Decline of Public Investment, September 2008

2385 Marko Koethenbuerger, How Do Local Governments Decide on Public Policy in Fiscal Federalism? Tax vs. Expenditure Optimization, September 2008

2386 Ronald McKinnon and Gunther Schnabl, China’s Exchange Rate Impasse and the Weak U.S. Dollar, September 2008

2387 Yan-Leung Cheung, Yin-Wong Cheung and Alan T.K. Wan, A High-Low Model of Daily Stock Price Ranges, September 2008

2388 Louis Eeckhoudt and Harris Schlesinger, Changes in Risk and the Demand for Saving, September 2008

2389 Carsten Hefeker and Blandine Zimmer, Uncertainty and Fiscal Policy in an Asymmetric Monetary Union, September 2008

2390 Jay Pil Choi and Byung-Cheol Kim, Net Neutrality and Investment Incentives, September 2008

2391 Marcel Gérard, Financing Bologna, the Internationally Mobile Students in European Higher Education, September 2008

2392 Annette Alstadsæter and Knut Reidar Wangen, Corporations' Choice of Tax Regime when Transition Costs are Small and Income Shifting Potential is Large, September 2008

2393 António Afonso and Christophe Rault, 3-Step Analysis of Public Finances Sustainability: the Case of the European Union, September 2008

2394 Betsey Stevenson and Justin Wolfers, Economic Growth and Subjective Well-Being: Reassessing the Easterlin Paradox, September 2008

2395 Bernhard Eckwert and Itzhak Zilcha, Private Investment in Higher Education: Comparing Alternative Funding Schemes, September 2008 